OPEN ACCESS

Edited by:

Merce Pallas,

University of Barcelona, Spain

Reviewed by:

Ramesh Kandimalla,

Texas Tech University, USA

Laura Lorenzo-López,

University of A Coruña, Spain

*Correspondence:

Zhuo Zhang

zhangzwest@163.com

Received: 01 December 2016 Accepted: 23 January 2017

Published: 07 February 2017

Citation: Jiang $X$, Huang J, Song $D$, Deng $R$, Wei $J$ and Zhang $Z$ (2017) Increased Consumption of Fruit and Vegetables Is Related to a Reduced Risk of Cognitive Impairment and Dementia: Meta-Analysis.

Front. Aging Neurosci. 9:18. doi: 10.3389/fnagi.2017.00018

\section{Increased Consumption of Fruit and Vegetables Is Related to a Reduced Risk of Cognitive Impairment and Dementia: Meta-Analysis}

\author{
Xian Jiang ${ }^{1}$, Jiang Huang ${ }^{2}$, Daqiang Song ${ }^{3}$, Ru Deng ${ }^{1}$, Jicheng Wei ${ }^{1}$ and Zhuo Zhang ${ }^{3 *}$ \\ ${ }^{1}$ Department of Anesthesia, The Affiliated Hospital of Southwest Medical University, Luzhou, China, ${ }^{2}$ Department of \\ Pharmacy, The Affiliated Traditional Chinese Medicine Hospital of Southwest Medical University, Luzhou, China, \\ ${ }^{3}$ Department of Pharmacology, School of Pharmacy of Southwest Medical University, Luzhou, China
}

Background: Increased consumption of fruit and vegetables has been shown to be associated with a reduced risk of cognitive impairment and dementia in many epidemiological studies. The purpose of this study was to assess the strength of this association in a meta-analysis.

Methods: We identified relevant studies by searching Medline, Embase, and Cochrane Library electronic databases (from 1970 to January 2016). Study were included if they reported relative risks and corresponding 95\% confidence intervals (Cls) of cognitive impairment and dementia with respect to frequency of fruit and vegetable intake.

Results: Nine studies (five cohort studies and four cross-sectional studies) met the inclusion criteria and were included in the meta-analysis. There were a total of 31,104 participants and 4,583 incident cases of cognitive impairment and dementia. The metaanalysis showed that an increased consumption of fruit and vegetables was associated with a significant reduction in the risk of cognitive impairment and dementia ( $O R=0.80$, $95 \%$ Cl 0.71-0.89). Subgroup analysis indicated this inverse association was only found among participants with mean age over 65 years and combined sexes. Dose-response meta-analysis showed that an increment of $100 \mathrm{~g}$ per day of fruit and vegetable consumption was related to an approximately $13 \%$ (OR $=0.87,95 \% \mathrm{Cl} 0.77-0.99)$ reduction in cognitive impairment and dementia risk. There was no potential publication bias in the meta-analysis and the dose-response meta-analysis.

Conclusion: The increased consumption of fruit and vegetables is associated with a reduced risk of cognitive impairment and dementia.

Keywords: fruit, vegetable, cognitive impairment, dementia, meta-analysis

\section{INTRODUCTION}

Cognitive impairment is an important public health concern, with a prevalence that is expected to rise with the population aging. It is a transitional stage between normal aging and dementia. Interventions may be particularly effective at earlier stages of disease development, which offer an opportunity for reducing the public health burden of Alzheimer's disease (AD) and other dementias through early detection and prevention (Morris et al., 1991; Roberts et al., 2010).

A number of epidemiologic researches and animal models have found associations between dietary components and age-related cognitive impairment and dementia (Joseph et al., 2009; Aparicio Vizuete et al., 2010; Gu and Scarmeas, 2011; Bondonno et al., 2014; Wu et al., 2015), 
and adherence to a Mediterranean-type diet was associated with slower cognitive decline and a reduced risk for $\mathrm{AD}$ in elderly individuals (Feart et al., 2009; Scarmeas et al., 2009). Fruit and vegetables are important components of a Mediterranean diet, which are high in antioxidants, vitamins, and folate, and in epidemiological and laboratory studies (Paleologos et al., 1998; Engelhart et al., 2002; Liu et al., 2002), these micronutrients have been related to cognitive benefits. Ye et al. (2013) found high variety of fruit and vegetable consumption was associated with individual cognitive domains, including executive function, memory and attention. A previous review of several cohort studies has examined the association between fruit and vegetable consumption and cognitive decline or dementia (Loef and Walach, 2012). In general, these studies find a favorable relation between fruit and vegetable consumption and risk of dementia or cognitive decline, although sometimes the results are inconsistent. Moreover, the strength of the favorable relation remains uncertain due to the differences in sample selections, methodological approaches, analytical techniques, and outcome definitions. Therefore, we conducted a meta-analysis to quantitatively assess the relation between fruit and vegetable consumption and the risk of cognitive impairment and dementia.

\section{MATERIALS AND METHODS}

\section{Search Strategy and Eligibility Criteria}

We followed the guidelines published by the Meta-analysis of Observational Studies in Epidemiology (MOOSE) group to complete the meta-analysis (Supplementary Table S1) (Stroup et al., 2000). Two investigators performed a systematic literature search of Medline, Embase, and Cochrane Library electronic databases (from 1970 to January 2016) to identify eligible articles. The electronic search includes both $\mathrm{MeSH}$ and freetext terms. The following terms were used: "Fruit," "Vegetables," "Mild Cognitive Impairment," "Dementia," "cognitive decline," "cognitive impairment," "survey," and "Data Collection." The references of all retrieved articles and recent reviews were also manually reviewed. The search strategy was not limited by study design. No attempt was made to find articles in languages other than English or to contact authors of unpublished works.

A study was eligible for inclusion if the following criteria were met: (1) examination of dietary consumption of fruit and/or vegetables as the variable of interest; (2) determination of incidence of cognitive impairment or dementia as the outcome of interest; and (3) reporting the relative risks of cognitive impairment or dementia calculated according to the highest category with the lowest category of fruit and/or vegetables consumption, and their 95\% confidence intervals (CIs). The studies about animal experiment, mechanistic research, and review research were excluded.

\section{Data Extraction and Study Quality Evaluation}

Two researchers independently extracted the following data from each publication: author, country, study design, sample size, disease type (cognitive impairment or dementia), number of cases, age, disease ascertainment, exposure variable (fruit, vegetable, or fruit and vegetable), exposure assessment, risk estimates with CIs, and factors adjusted for. The most adjusted estimate was included when a study reported more than one risk estimate. The quality of each study was assessed by two researchers, using the Newcastle-Ottawa Scale recommended by Wells et al. (2011).

\section{Statistical Analysis and Data Synthesis}

We performed meta-analyses of risk estimates for cognitive impairment and dementia comparing the highest category of exposure of fruit and vegetables with the lowest category. We pooled the data on cognitive impairment and dementia together, since there were limited studies on each single disease. Dose-response meta-analyses of fruit and vegetable consumption and risk of cognitive impairment and dementia were then conducted using methods previously reported (Greenland and Longnecker, 1992; Larsson and Orsini, 2011), which facilitated the calculation of a pooled relative risk across studies with a common unit of comparison with studies, assuming a linear dose-response relation. In the current study, we estimated the relative risk per unit of $100 \mathrm{~g}$ increment of fruit and vegetable consumption per day for each study and then pooled them together. For studies that reported results for fruit and/or vegetable consumption in servings only, we derived grams by assuming that the average serving equals $80 \mathrm{~g}$ for fruits and $77 \mathrm{~g}$ for vegetables (He et al., 2007). We converted the level of fruit and vegetable consumption categories based on the calculated midpoint of fruit and vegetable consumption if the study did not report the median of exposure category. Supplementary Table S2 shows the definition of fruit and vegetable consumption and the means of conversion of categories within each study.

We used a fixed effects model to estimate the pooled ORs and 95\% CI if there was no evidence of heterogeneity; otherwise, a random effect model was used. The $I$-squared $\left(I^{2}\right)$ statistic and $Q$-statistic were used to explore the heterogeneity among studies. Large $I^{2}(>50 \%)$ or $P<0.10$ for $Q$-statistic suggests substantial heterogeneity among studies. We also performed a sensitivity analysis by removing each individual study from the meta-analysis (Tobias, 1999). Publication bias was visually assessed by using funnel plots. Egger's regression test (Egger et al., 1997) and Begg-Mazumdar test (Begg and Mazumdar, 1994) were used to further assess publication bias. Subgroup analyses were performed according to the mean age of sample, sex, geographic location, study design, study quality score, disease type, and dietary assessment method. Statistical analyses were conducted using Stata Version 12.0 software (Stata Corp., College Station, TX, USA).

\section{RESULTS}

\section{Search Results}

Of the 359 citations identified from database searches, nine articles met the inclusion criteria and were included in the meta-analysis, including five cohort studies (Barberger-Gateau et al., 2007; Vercambre et al., 2009; Hughes et al., 2010; Ritchie 


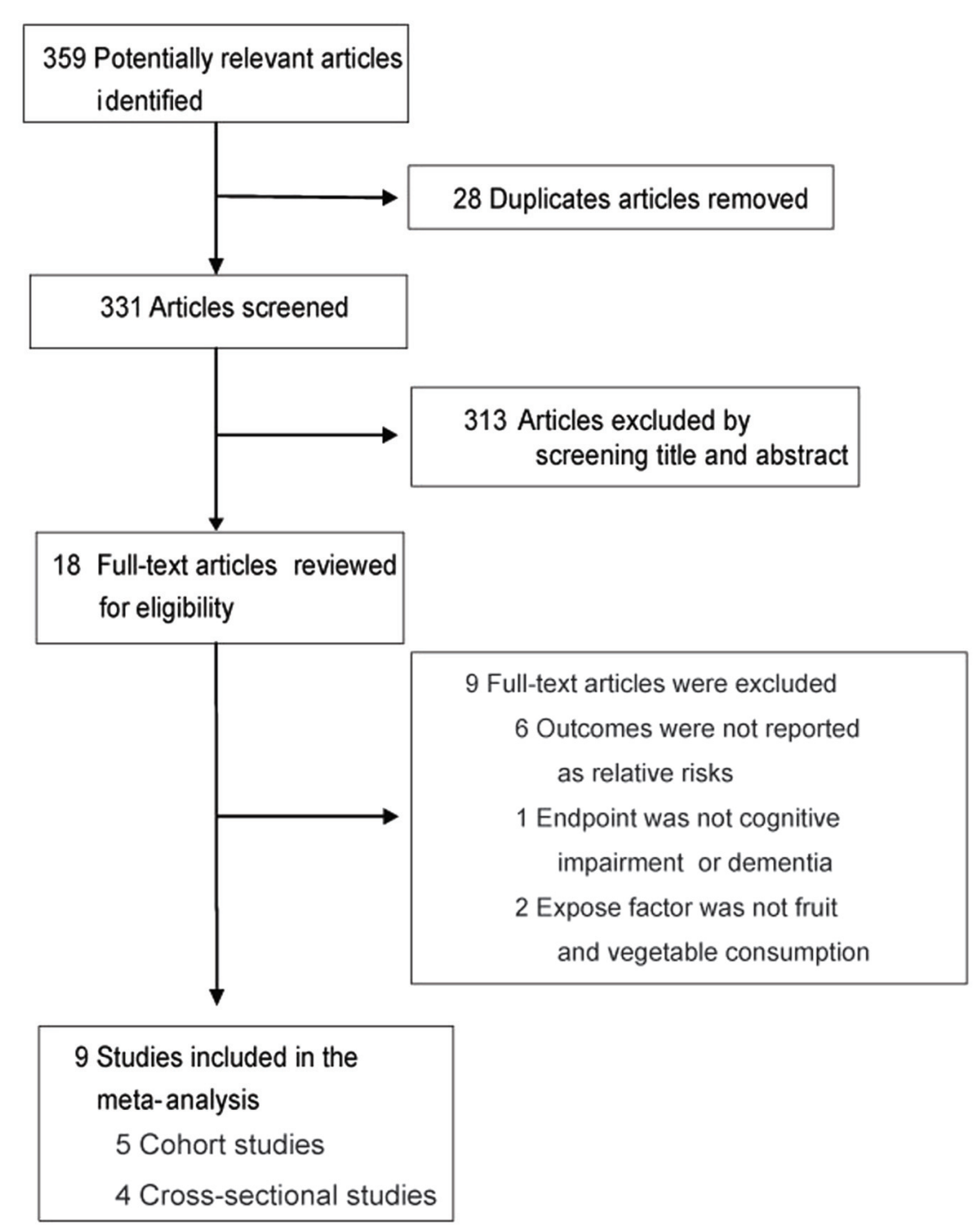

FIGURE 1 | Flowchart for the selection of eligible studies.

et al., 2010; Chen et al., 2012) and four cross-sectional studies (Lee et al., 2010; Roberts et al., 2010; Wu et al., 2011; Chan et al., 2013). The study selection process is shown in Figure 1. Among the included studies, four were from Europe, four were from China, and one was from the United States. Table 1 summarizes the characteristics of the included studies. The analysis involved a total of 31,104 participants and 4,583 incident cases of cognitive impairment and dementia. Frequency of fruit and vegetable consumption was recorded in different categories from the least frequent consumption to the most frequent consumption. We recorded relative risks of cognitive impairment and dementia according to the highest vs. lowest category of fruit and vegetable consumption. The quality assessment of the included studies was presented in detail in the supplementary material (Supplementary Tables S3 and S4).

\section{Meta-Analysis}

Figure 2 shows the results of meta-analysis of relative risk according to the highest vs. lowest category of fruit and vegetable consumption. The summary result showed that high fruit and vegetable consumption was associated with a reduced risk of cognitive impairment and dementia (OR $=0.80,95 \%$ CI $0.71-$ 0.89). A significant heterogeneity was observed for the pooled analyses $\left(I^{2}=55.2 \%, P=0.005\right)$. Subgroup analyses showed that the inverse association between fruit and vegetable consumption and risk of cognitive impairment and dementia was only found in the participants with mean age over 65 years $(\mathrm{OR}=0.80,95 \%$ CI 0.71-0.91) and combined sexes (OR $=0.71$, 95\% CI $0.66-$ 0.78 ), and studies from the United States and with full marks of study quality score did not show statistical significances (Table 2). Sensitivity analysis indicated that the inverse association was not 


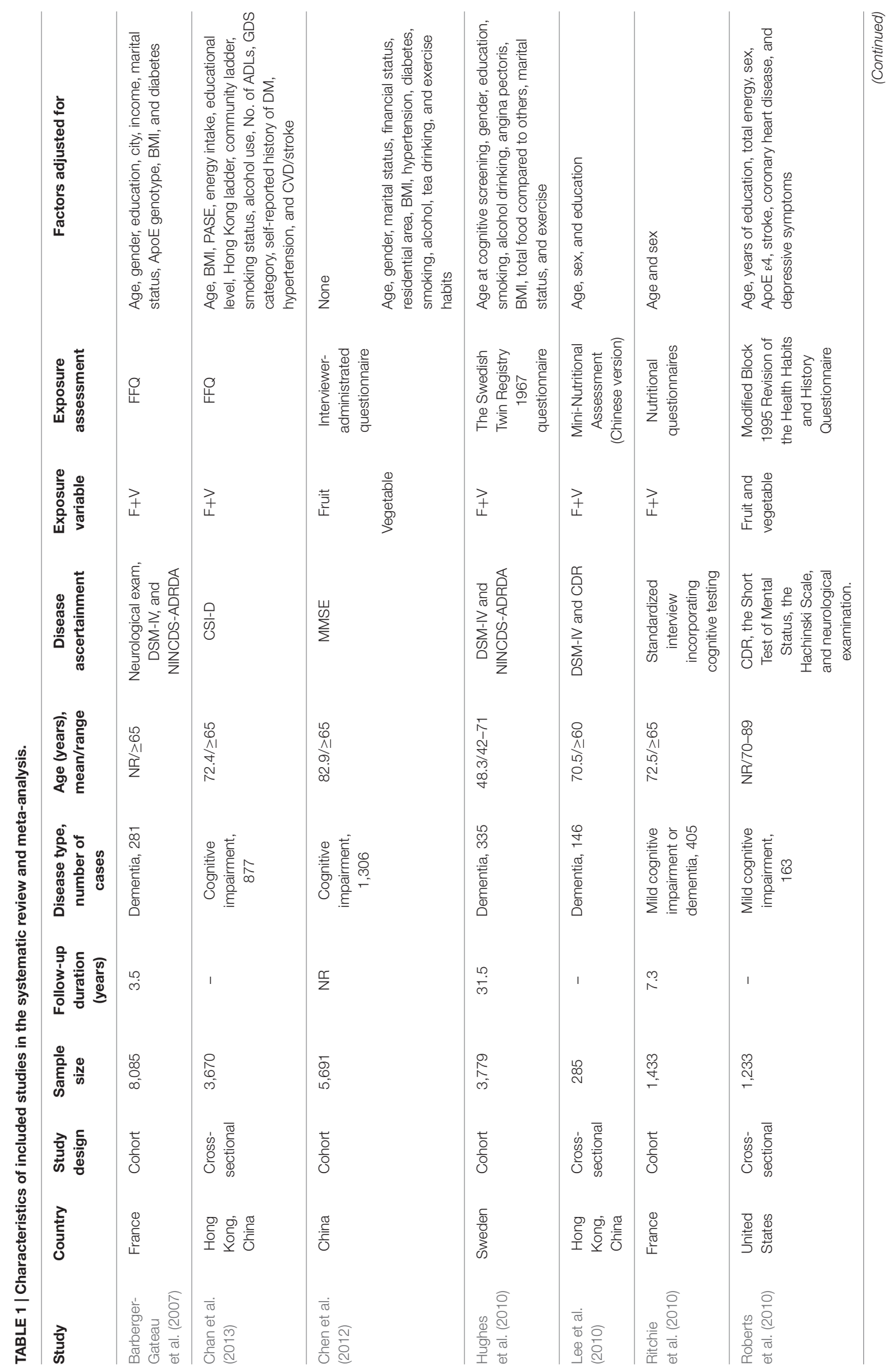




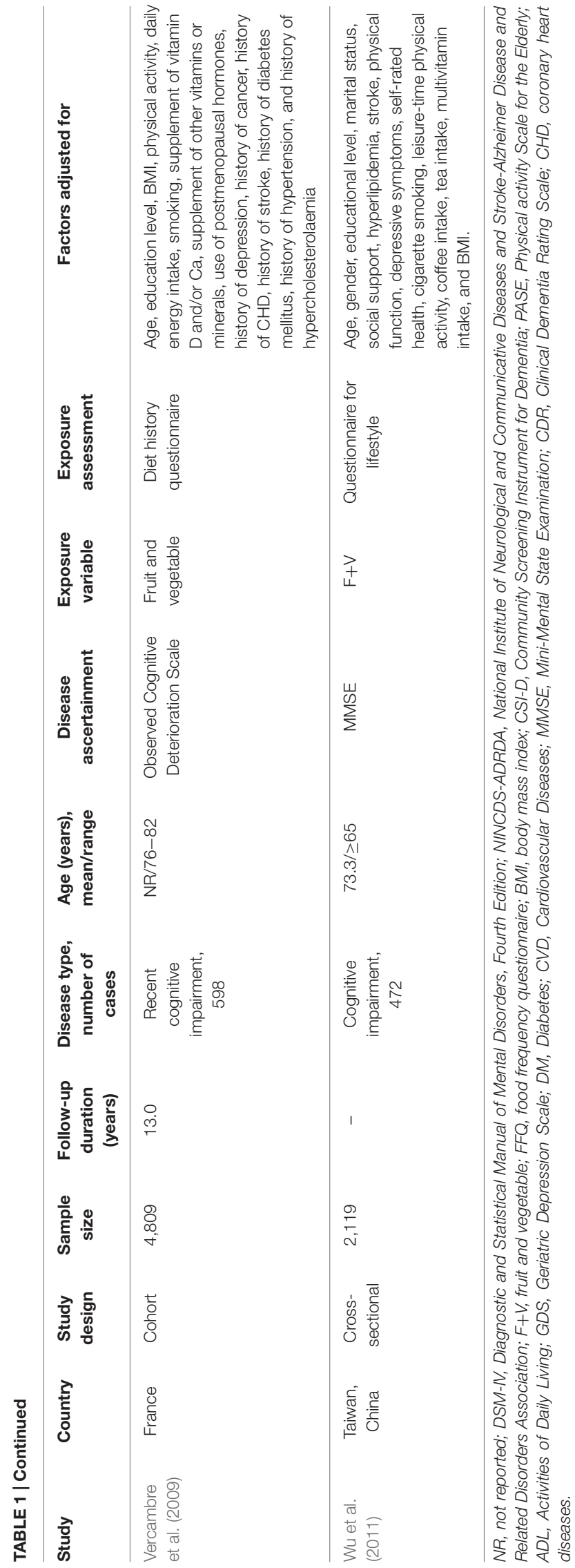

TABLE 2 | Subgroup analysis for studies included in the analysis.

\begin{tabular}{|c|c|c|}
\hline \multirow[t]{2}{*}{ Subgroup analysis } & \multicolumn{2}{|c|}{$\begin{array}{c}\text { Pooled OR (95\% Cl), } P \text {-value for the heterogeneity } \\
Q \text { test, } I^{2} \text { statistics }(\%) \text {, number of estimates in } \\
\text { included studies }(n)\end{array}$} \\
\hline & $n$ & $\begin{array}{l}\text { Risk estimates of cognitive } \\
\text { impairment and dementia }\end{array}$ \\
\hline \multicolumn{3}{|l|}{ Mean age } \\
\hline$\geq 65$ years & 12 & $0.80(0.71-0.91) ; l^{2}=54.7, P=0.012$ \\
\hline$<65$ years & 3 & $0.79(0.51-1.21) ; I^{2}=70.8, P=0.032$ \\
\hline \multicolumn{3}{|l|}{ Sex } \\
\hline Female & 4 & $0.82(0.64-1.06) ; P^{2}=71.9, P=0.014$ \\
\hline Male & 2 & $1.18(0.85-1.63) ; P^{2}=0.0, P=0.571$ \\
\hline Combined & 9 & $0.71(0.66-0.78) ; P^{2}=0.0, P=0.567$ \\
\hline \multicolumn{3}{|l|}{ Geographic location } \\
\hline Europe & 7 & $0.84(0.70-0.99) ; P^{2}=60.8, P=0.018$ \\
\hline United States & 2 & $0.78(0.58-1.04) ; P^{2}=21.9, P=0.258$ \\
\hline China & 6 & $0.71(0.64-0.78) ; P^{2}=38.0, P=0.153$ \\
\hline \multicolumn{3}{|l|}{ Study design } \\
\hline Cohort & 9 & $0.80(0.69-0.92) ; P^{2}=67.5, P=0.002$ \\
\hline Cross-sectional & 6 & $0.80(0.67-0.95) ; P^{2}=23.5, P=0.257$ \\
\hline \multicolumn{3}{|l|}{ Study quality score ${ }^{a}$} \\
\hline Full marks & 7 & $0.91(0.81-1.02) ; P^{2}=28.1, P=0.214$ \\
\hline Not full marks & 8 & $0.71(0.65-0.77) ; P^{2}=40.9, P=0.106$ \\
\hline \multicolumn{3}{|l|}{ Disease type } \\
\hline Cognitive impairment & 10 & $0.82(0.72-0.93) ; P^{2}=57.8, P=0.011$ \\
\hline Dementia & 5 & $0.73(0.54-0.83) ; P^{2}=56.9, P=0.054$ \\
\hline \multicolumn{3}{|c|}{ Dietary assessment method } \\
\hline FFQ & 3 & $0.79(0.65-0.96) ; P^{2}=30.2, P=0.239$ \\
\hline Others & 12 & $0.79(0.69-0.91) ; P^{2}=61.2, P=0.003$ \\
\hline
\end{tabular}

OR, odds ratio; Cl, confidence interval; FFQ, food frequency questionnaire. aFull mark was defined as nine points for cohort studies and five points for crosssectional studies based on the Newcastle-Ottawa Scale.

materially changed in the leave-one-out analyses by omitting one study in turn, with a pooled OR of cognitive impairment and dementia range from 0.74 (95\% CI $0.69-0.80)$ to 0.83 ( $95 \%$ CI $0.76-0.90$ ) for the highest vs. lowest category of fruit and vegetable consumption (Figure 3).

\section{Dose-Response Meta-Analysis}

Only four estimates from three individual studies were included in the dose-response meta-analysis, because there were only two categories of fruit and vegetable consumption in other studies, and dose-response meta-analysis requires data for the distribution of cases and person-time across at least three categories of exposure (Alexander et al., 2009). In the dose-response meta-analysis, the reduced risk of cognitive impairment and dementia by an increment of $100 \mathrm{~g}$ per day of fruit and vegetable consumption was only observed in the estimate for vegetable in Roberts et al.'s study. However, the pooled result showed that an increment of $100 \mathrm{~g}$ per day of fruit and vegetable consumption was associated with a reduced risk of cognitive impairment and dementia ( $\mathrm{OR}=0.87,95 \%$ CI 0.77-0.99) (Figure 4). There was no potential heterogeneity among studies $\left(I^{2}=39.8 \%, P=0.173\right)$. 


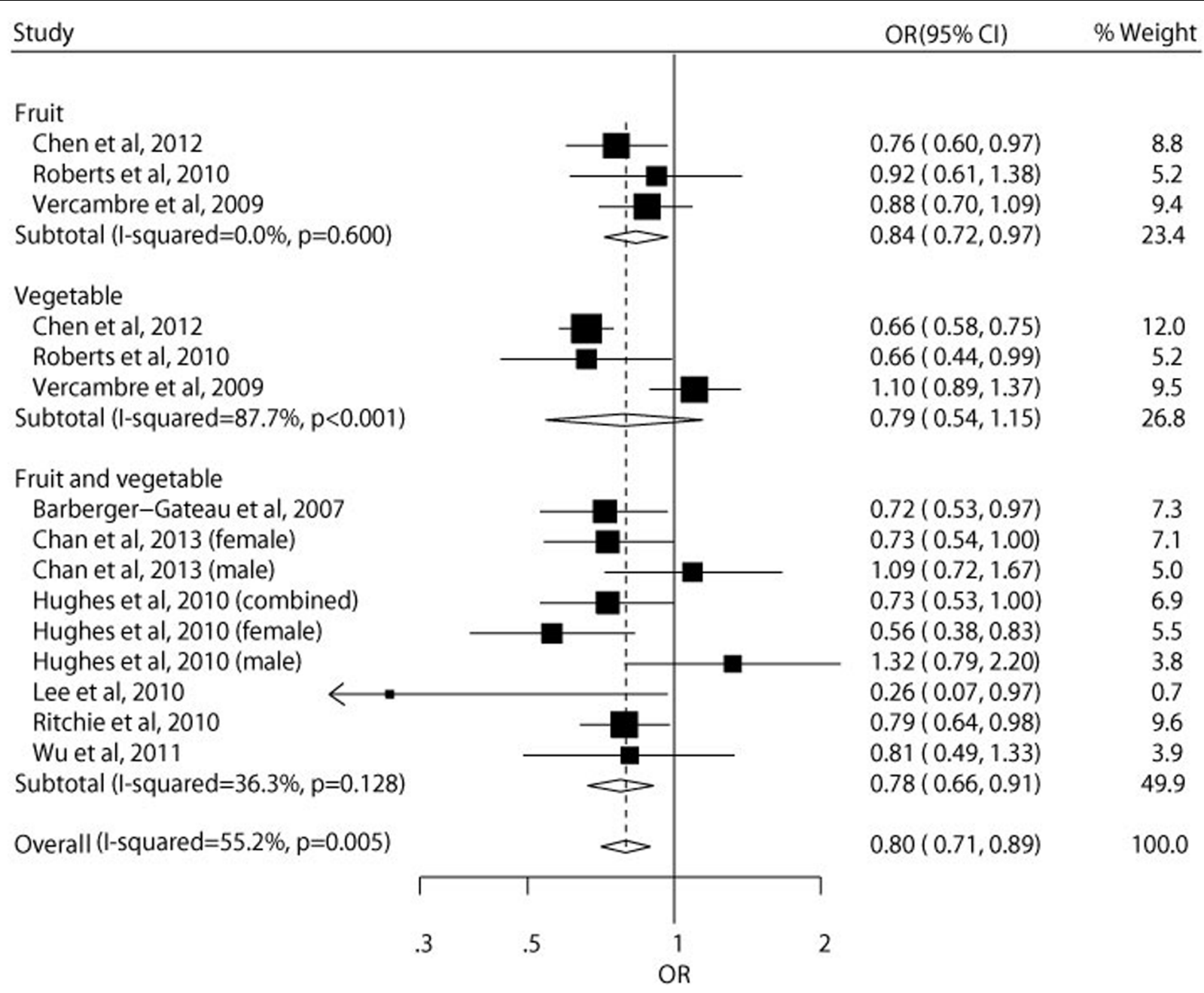

FIGURE 2 | Relative risk of cognitive impairment and dementia according to the highest vs. lowest category of fruit and vegetables consumption.

\section{Publication Bias}

Visual assessment of funnel plots (Figure 5) showed that the studies were distributed fairly symmetrically about the combined effect size in both the meta-analysis and the dose-response metaanalysis, which suggests little publication bias. Egger's regression test ( $P=0.624$ and $P=0.273$, respectively) and Begg-Mazumdar test $(P=0.882$ and $P=1.000$, respectively) also showed that there was no potential publication bias in the meta-analysis and the dose-response meta-analysis.

\section{DISCUSSION}

We have quantitatively assessed the relation between fruit and vegetable consumption and risk of cognitive impairment and dementia through a meta-analysis of existing epidemiological studies. Evidence from the literature is mixed. Some studies indicate that fruit and vegetable intake has a protective effect on global cognitive performance (Nurk et al., 2010) and memory and executive function (Sabia et al., 2009), and people with high intakes of fruit and vegetables score higher on cognitive tests and are less likely to have cognitive decline and lower incidence of dementia (Gillette Guyonnet et al., 2007), whereas others suggest nonsignificant effects of fruit and vegetable intake on cognitive flexibility, memory, and information processing speed (Nooyens et al., 2011); perceptual speed and attention (Morris et al., 2006); or verbal memory, general cognition, working memory, and category fluency (Kang et al., 2005). Overall, measurement limitations, as well as the type of cognitive function measured, the types of fruit and vegetables consumed, or amounts of fruit and vegetable intake might have led to the inconsistence in the observed results. The value of the current meta-analysis compensates for the individual lack of precision in most of the studies, a problem that was alleviated by pooling the data of all the studies. Therefore, meta-analysis of these studies is a potentially powerful approach to assess the long-term effects of fruit and vegetable consumption on cognitive impairment and dementia risk. Our study shows that an increased consumption of fruit and vegetables is related to a reduced risk of cognitive impairment and dementia. Moreover, we found an increment of $100 \mathrm{~g}$ per day of 


\section{Study omitted}

Chen et al, 2012 (fruit) Roberts et al, 2010 (fruit) Vercambre et al, 2009 (fruit) Chen et al, 2012 (vegetable) Roberts et al, 2010 (vegetable) Vercambre et al, 2009 (vegetable) Barberger-Gateau et al, 2007 Chan et al, 2013 (female) Chan et al, 2013 (male) Hughes et al, 2010 (combined) Hughes et al, 2010 (female) Hughes et al, 2010 (male) Lee et al, 2010

Ritchie et al, 2010

Wu et al, 2011

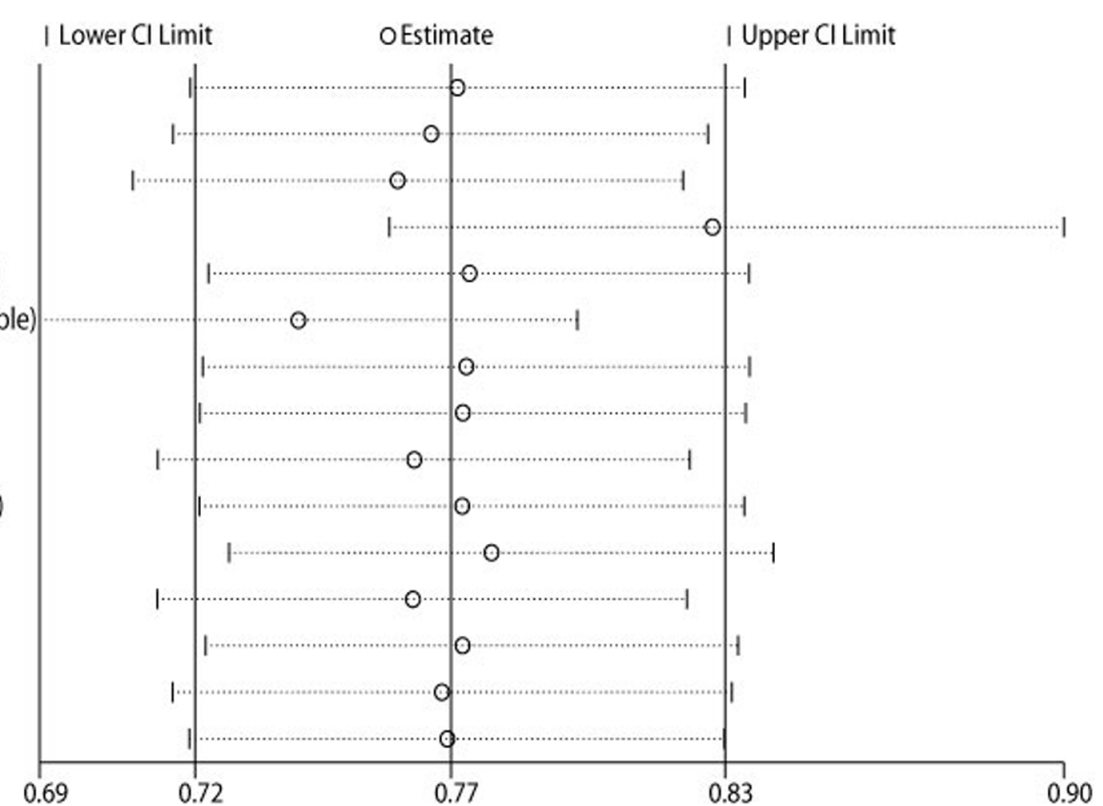

FIGURE 3 | Sensitivity analysis. Relative risk of cognitive impairment and dementia according to the highest vs. lowest category of fruit and vegetables consumption by omitting one study in turn.

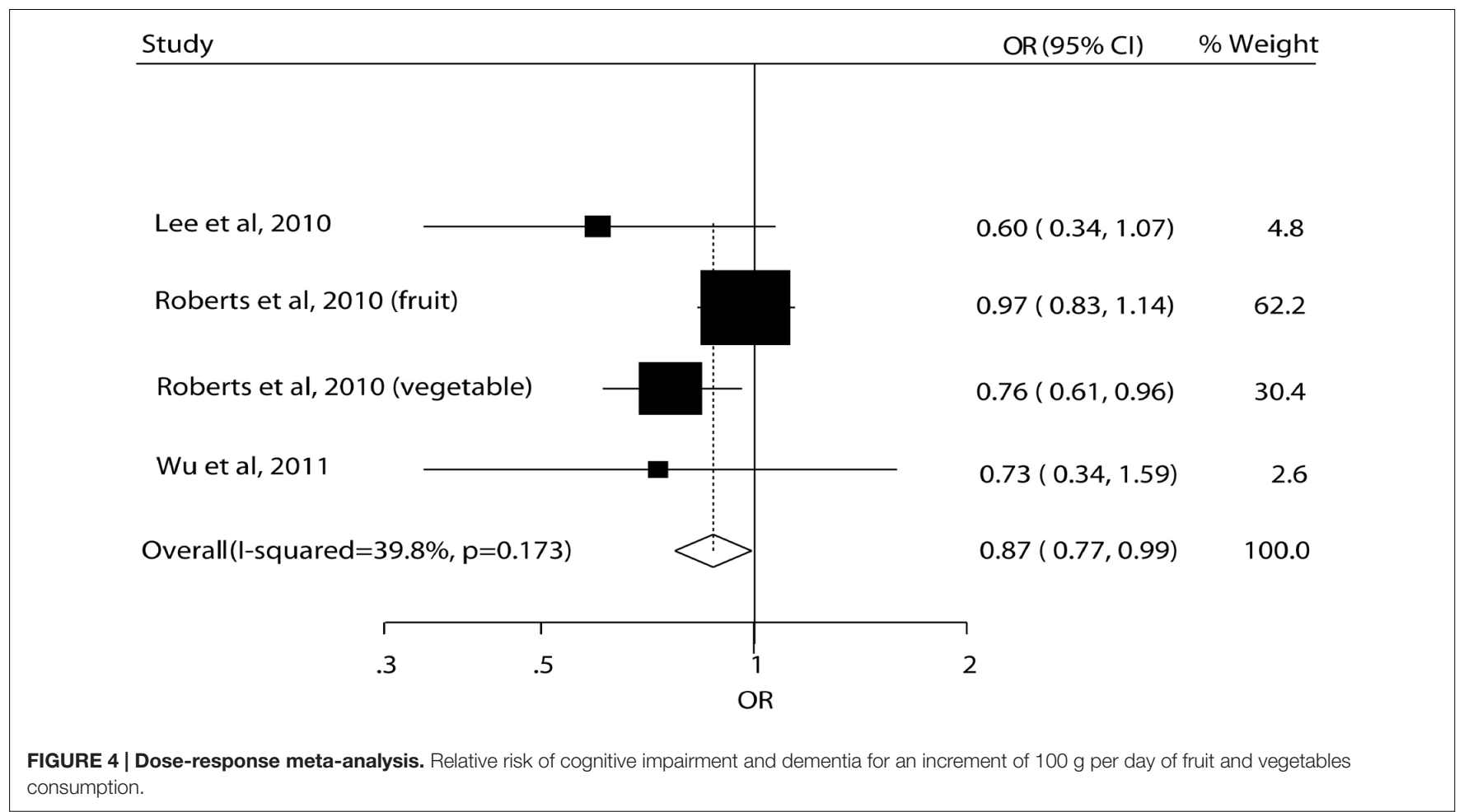

fruit and vegetable consumption was related to an approximately $13 \%$ reduction in cognitive impairment and dementia risk.

Our findings extend the results of a previous systematic review (Loef and Walach, 2012), which found increased intake of vegetables was associated with a lower risk of dementia and slower rates of cognitive decline in older age but evidence that this association is also valid for high fruit consumption is lacking. Morris et al. (2006) also found that high vegetable but not fruit consumption may be associated with slower rate of cognitive decline with older age. Interestingly, in our 


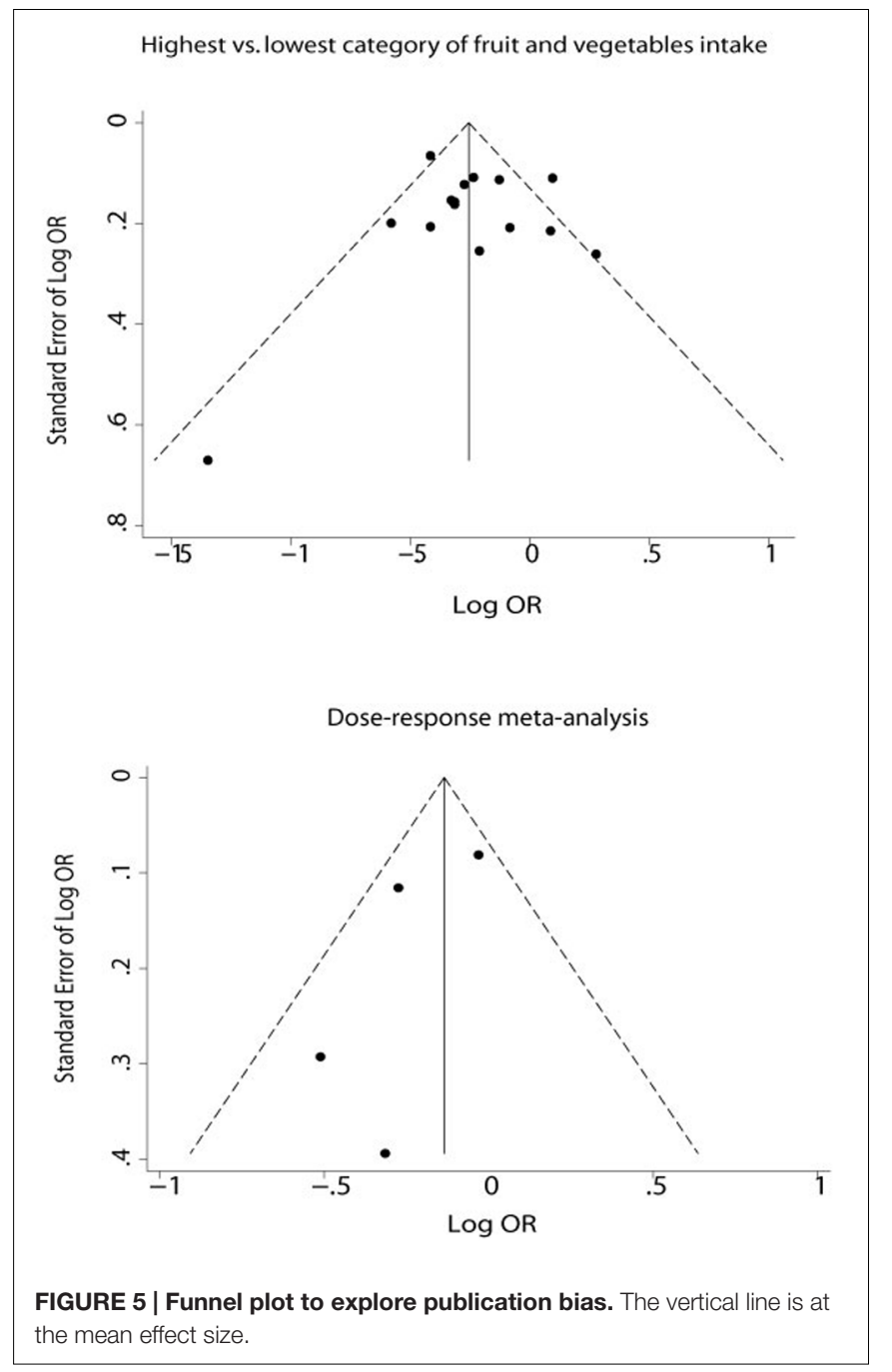

subtotal estimates, we found that fruit and fruit and vegetable combined but not vegetable consumption had a protective effect on cognitive impairment and dementia (Figure 2). But in our meta-analysis, most included studies used fruit and vegetable combined as the exposure variable, and there were only three studies included in the subtotal estimates of both fruit alone and vegetable alone, leading to a low statistical power. This is also the reason why we pooled the results of fruit alone, vegetable alone, and fruit and vegetable combined together. More studies are needed to further assess the role of fruit and vegetable separately on the risk of cognitive impairment and dementia. In addition, our meta-analysis restricted to overall fruit and vegetable consumption, some particular kinds of fruit and vegetable intake, such as nuts, cruciferous vegetables, dark and green leafy vegetables, root vegetables, cabbage, tomatoes, soybeans, and soybean products (Kang et al., 2005; Gu et al., 2010; Nooyens et al., 2011; Ozawa et al., 2013), may also have a protective role on cognitive impairment and dementia risk, but they were not included in our metaanalysis due to the limited data. More investigations focusing on the association between these specific fruits and vegetables and cognitive impairment and dementia risk are also urgently needed.

Epidemiological and animal investigations support the protective effect of fruit and vegetables against cognitive impairment and dementia. The brain is extremely susceptible to oxidative damage (Floyd and Hensley, 2002), and fruits and vegetables are high in antioxidants (Proteggente et al., 2002). Some epidemiological studies (Engelhart et al., 2002; Morris et al., 2002; Grodstein et al., 2003; Zandi et al., 2004) have reported that high intake of antioxidants is related to reduced cognitive decline or dementia. Furthermore, animal studies have indicated that antioxidants prevent neuronal damage (Maneesub et al., 1993; Yokota et al., 2001) and improve cognitive performance (Sack et al., 1996; Cotman et al., 2002). A study from the rats model suggests that the antioxidant vitamins found in green leafy vegetables could be particular important for cognitive health (Joseph et al., 1999). Epidemiological studies (Ebly et al., 1998; Lindeman et al., 2000; Seshadri et al., 2002) has also found that folate in some fruits and vegetables is linked to cognitive function and dementia. Folate deficiency can increase the level of homocysteine, which has direct neurotoxic effects in cell lines and animal models (Lipton et al., 1997; Kruman et al., 2002). In contrast, other facts are not in favor of a causal relation. Generally, fruit and vegetable consumers have healthier lifestyles and dietary pattern, which themselves are associated with better cognitive performance (Evans et al., 1997; KesseGuyot et al., 2012). Although most studies have adjusted for lifestyle factors, residual confounders may still explain part of the favorable association with cognitive performance and dementia. High consumptions of fruit and vegetables are associated with a prudent diet pattern, and inversely related to the intake of saturated fat-rich food (Tucker et al., 2005), which may also contribute to the lower risk of cognitive impairment and dementia (Kalmijn et al., 1997). Therefore, the results of current study support the concept that the regular intake of fruit and vegetables is associated with reduced risk of cognitive impairment and dementia, however, it does not establish a causal relation. Well designed randomized controlled trials that address a specific mechanism of fruit and vegetables consumption and reduced risk of cognitive impairment and dementia are needed.

In subgroup analyses, we found that there was a statistically significant inverse association between fruit and vegetable consumption and cognitive impairment and dementia risk in participants with mean age over 65 years, but not in those with mean age less than 65 years. This may be because that the incidence of cognitive impairment and dementia increases sharply with the age grows. Thus, the protective effects of fruit and vegetables against cognitive impairment and dementia are more prominent among the older populations. Notably, the null inverse association in younger participants might also result from the limited number of included studies. More studies are warranted to investigate the potential difference between the different age groups. In the subgroup analysis of geographic location, we found the pooled OR for China was much smaller than that for Europe and the United States (0.71 with 95\% CI $0.64-0.78,0.84$ with $95 \%$ CI $0.64-0.78$, and 0.78 with 95\% CI 0.58-1.04 for China, Europe, and the United States, 
respectively). This means that the protective effects of fruit and vegetables against cognitive impairment and dementia are stronger for Chinese populations than the Western populations. This may be explained by the different dietary patterns and food preparation methods between Chinese and Western populations. Firstly, the proportion of saturated fat-rich food is higher in the Western dietary pattern, which may increase the risk of cognitive impairment and dementia as discussed above. Secondly, in Western world, people mainly eat raw vegetables, such as in the form of salad, while the Chinese populations often eat cooked, steamed, or boiled vegetables. Usually, people tend to eat more vegetables after being cooked, and the cooked vegetables can be more easily digested because the cell wall of raw vegetables is relatively harder, which will increase the burden of digestion. In addition, studies show that the nutritional quality increases in all cooked vegetables because of matrix softening and increased extractability of compounds, which could be partially converted into more antioxidant chemical species (Miglio et al., 2008; Porrini and Riso, 2008).

The strengths of the present meta-analysis include the considerable number of studies and subjects included, as well as the acceptable methodologic quality of the studies on which the analysis is based. The study has several limitations. Firstly, a substantial heterogeneity across studies was apparent in the meta-analysis. The heterogeneity was not accounted by age, sex, geographic location, study design, disease type, and dietary assessment method. However, the subgroup analysis for study quality score reduced the heterogeneity, which means the study quality is a main source of heterogeneity. Secondly, the assessment for fruit and vegetable consumption is mostly based on self-reported habits, and such data are subject to recall errors. In addition, there were many other differences among studies, including dietary assessment methods, the variety of fruit or vegetables investigated, the definition of the reference group, and the choice of exposure categories. These differences could affect the estimation of the true relation. Thirdly, the metaanalysis is based on observational studies, which leaves the possibility that potential confounders cannot be ruled out, affect the relation between fruit and vegetable consumption and risk of cognitive impairment and dementia. A meta-analysis is not able to solve problems with confounding that may be inherent in the included studies. However, most studies have made adjustment of major confounding factors, which should reduce the potential bias due to the dietary and lifestyle factors. Finally, due to the

\section{REFERENCES}

Alexander, D. D., Cushing, C. A., Lowe, K. A., Sceurman, B., and Roberts, M. A. (2009). Meta-analysis of animal fat or animal protein intake and colorectal cancer. Am. J. Clin. Nutr. 89, 1402-1409. doi: 10.3945/ajcn.2008. 26838

Aparicio Vizuete, A., Robles, F., Rodriguez-Rodriguez, E., Lopez-Sobaler, A. M., and Ortega, R. M. (2010). Association between food and nutrient intakes and cognitive capacity in a group of institutionalized elderly people. Eur. J. Nutr. 49, 293-300. doi: 10.1007/s00394-009$0086-y$ limited studies, we combined consumption of fruit and vegetable together as the exposure variable and cognitive impairment and dementia together as the outcome. The effects of fruit and vegetable separately on cognitive impairment or dementia should be further investigated in future studies.

\section{CONCLUSION}

This meta-analysis indicates significant inverse association between fruit and vegetable consumption and risk of cognitive impairment and dementia. The risk of cognitive impairment and dementia was reduced by $20 \%$ for a higher consumption of fruit and vegetables, and by $13 \%$ for an increment of $100 \mathrm{~g}$ per day of fruit and vegetable consumption. For further studies, based on our findings, we suggest that the investigators should improve the standardization of various dietary assessment methods, which may make the results more accurate and conceivable. Furthermore, the use of genetic and biological makers as surrogate end points in the future studies should help to clarify the cause and effect relationship that link fruit and vegetable consumption and cognitive impairment and dementia.

\section{AUTHOR CONTRIBUTIONS}

ZZ designed the study. JH, DS, and RD collected the data. XJ performed all analyses. XJ, JH, JW, and ZZ wrote the manuscript. All authors contributed to writing of this manuscript.

\section{ACKNOWLEDGMENTS}

This study is supported by Education Department of Sichuan Province (13ZB0267), projects by Luzhou Municipal Science and Technology Bureau \& Luzhou Medical College (14JC0181 and 2013LZLY-J52), and Science and Technology Department of Sichuan Province (2014SZ0071).

\section{SUPPLEMENATRY MATERIAL}

The Supplementary Material for this article can be found online at: http://journal.frontiersin.org/article/10.3389/fnagi. 2017.00018/full\#supplementary-material

Barberger-Gateau, P., Raffaitin, C., Letenneur, L., Berr, C., Tzourio, C., Dartigues, J. F., et al. (2007). Dietary patterns and risk of dementia: the ThreeCity cohort study. Neurology 69, 1921-1930. doi: 10.1212/01.wnl.0000278116. 37320.52

Begg, C. B., and Mazumdar, M. (1994). Operating characteristics of a rank correlation test for publication bias. Biometrics 50, 1088-1101. doi: 10.2307/ 2533446

Bondonno, C. P., Downey, L. A., Croft, K. D., Scholey, A., Stough, C., Yang, X., et al. (2014). The acute effect of flavonoid-rich apples and nitrate-rich spinach on cognitive performance and mood in healthy men and women. Food Funct. 5, 849-858. doi: 10.1039/c3fo60590f 
Chan, R., Chan, D., and Woo, J. (2013). A cross sectional study to examine the association between dietary patterns and cognitive impairment in older Chinese people in Hong Kong. J. Nutr. Health Aging 17, 757-765. doi: 10.1007/s12603013-0348-5

Chen, X., Huang, Y., and Cheng, H. G. (2012). Lower intake of vegetables and legumes associated with cognitive decline among illiterate elderly Chinese: a 3 -year cohort study. J. Nutr. Health Aging 16, 549-552. doi: 10.1007/s12603012-0023-2

Cotman, C. W., Head, E., Muggenburg, B. A., Zicker, S., and Milgram, N. W. (2002). Brain aging in the canine: a diet enriched in antioxidants reduces cognitive dysfunction. Neurobiol. Aging 23, 809-818. doi: 10.1016/S01974580(02)00073-8

Ebly, E. M., Schaefer, J. P., Campbell, N. R., and Hogan, D. B. (1998). Folate status, vascular disease and cognition in elderly Canadians. Age Ageing 27, 485-491. doi: 10.1093/ageing/27.4.485

Egger, M., Davey Smith, G., Schneider, M., and Minder, C. (1997). Bias in metaanalysis detected by a simple, graphical test. BMJ 315, 629-634. doi: 10.1136/ bmj.315.7109.629

Engelhart, M. J., Geerlings, M. I., Ruitenberg, A., van Swieten, J. C., Hofman, A., Witteman, J. C., et al. (2002). Dietary intake of antioxidants and risk of Alzheimer disease. JAMA 287, 3223-3229. doi: 10.1001/jama.287.24.3223

Evans, D. A., Hebert, L. E., Beckett, L. A., Scherr, P. A., Albert, M. S., Chown, M. J., et al. (1997). Education and other measures of socioeconomic status and risk of incident Alzheimer disease in a defined population of older persons. Arch. Neurol. 54, 1399-1405. doi: 10.1001/archneur.1997.00550230066019

Feart, C., Samieri, C., Rondeau, V., Amieva, H., Portet, F., Dartigues, J. F., et al. (2009). Adherence to a Mediterranean diet, cognitive decline, and risk of dementia. JAMA 302, 638-648. doi: 10.1001/jama.2009.1146

Floyd, R. A., and Hensley, K. (2002). Oxidative stress in brain aging. Implications for therapeutics of neurodegenerative diseases. Neurobiol. Aging 23, 795-807. doi: 10.1016/S0197-4580(02)00019-2

Gillette Guyonnet, S., Abellan Van Kan, G., Andrieu, S., Barberger Gateau, P., Berr, C., Bonnefoy, M., et al. (2007). IANA task force on nutrition and cognitive decline with aging. J. Nutr. Health Aging 11, 132-152.

Greenland, S., and Longnecker, M. P. (1992). Methods for trend estimation from summarized dose-response data, with applications to meta-analysis. Am. J. Epidemiol. 135, 1301-1309.

Grodstein, F., Chen, J., and Willett, W. C. (2003). High-dose antioxidant supplements and cognitive function in community-dwelling elderly women. Am. J. Clin. Nutr. 77, 975-984.

Gu, Y., Nieves, J. W., Stern, Y., Luchsinger, J. A., and Scarmeas, N. (2010). Food combination and Alzheimer disease risk: a protective diet. Arch. Neurol. 67, 699-706. doi: 10.1001/archneurol.2010.84

Gu, Y., and Scarmeas, N. (2011). Dietary patterns in Alzheimer's disease and cognitive aging. Curr. Alzheimer Res. 8, 510-519. doi: 10.2174/ 156720511796391836

He, F. J., Nowson, C. A., Lucas, M., and MacGregor, G. A. (2007). Increased consumption of fruit and vegetables is related to a reduced risk of coronary heart disease: meta-analysis of cohort studies. J. Hum. Hypertens. 21, 717-728. doi: $10.1038 /$ sj.jhh.1002212

Hughes, T. F., Andel, R., Small, B. J., Borenstein, A. R., Mortimer, J. A., Wolk, A., et al. (2010). Midlife fruit and vegetable consumption and risk of dementia in later life in Swedish twins. Am. J. Geriatr. Psychiatry 18, 413-420. doi: 10.1097/ JGP.0b013e3181c65250

Joseph, J. A., Shukitt-Hale, B., Denisova, N. A., Bielinski, D., Martin, A., McEwen, J. J., et al. (1999). Reversals of age-related declines in neuronal signal transduction, cognitive, and motor behavioral deficits with blueberry, spinach, or strawberry dietary supplementation. J. Neurosci. 19, 8114-8121.

Joseph, J. A., Shukitt-Hale, B., and Willis, L. M. (2009). Grape juice, berries, and walnuts affect brain aging and behavior. J. Nutr. 139, 1813S-1817S. doi: 10. 3945/jn.109.108266

Kalmijn, S., Launer, L. J., Ott, A., Witteman, J. C., Hofman, A., and Breteler, M. M. (1997). Dietary fat intake and the risk of incident dementia in the Rotterdam Study. Ann. Neurol. 42, 776-782. doi: 10.1002/ana.410420514

Kang, J. H., Ascherio, A., and Grodstein, F. (2005). Fruit and vegetable consumption and cognitive decline in aging women. Ann. Neurol. 57, 713-720. doi: 10.1002/ana.20476
Kesse-Guyot, E., Andreeva, V. A., Jeandel, C., Ferry, M., Hercberg, S., and Galan, P. (2012). A healthy dietary pattern at midlife is associated with subsequent cognitive performance. J. Nutr. 142, 909-915. doi: 10.3945/jn.111.156257

Kruman, I. I., Kumaravel, T. S., Lohani, A., Pedersen, W. A., Cutler, R. G., Kruman, Y., et al. (2002). Folic acid deficiency and homocysteine impair DNA repair in hippocampal neurons and sensitize them to amyloid toxicity in experimental models of Alzheimer's disease. J. Neurosci. 22, 1752-1762.

Larsson, S. C., and Orsini, N. (2011). Fish consumption and the risk of stroke: a dose-response meta-analysis. Stroke 42, 3621-3623. doi: 10.1161/ STROKEAHA.111.630319

Lee, J., Lam, L., Woo, J., and Kwok, T. (2010). Lower fluid and fruits/vegetable intake in questionable dementia among older Hong Kong Chinese. J. Nutr. Health Aging 14, 45-49. doi: 10.1007/s12603-010-0008-y

Lindeman, R. D., Romero, L. J., Koehler, K. M., Liang, H. C., LaRue, A., Baumgartner, R. N., et al. (2000). Serum vitamin B12, C and folate concentrations in the New Mexico elder health survey: correlations with cognitive and affective functions. J. Am. Coll. Nutr. 19, 68-76. doi: 10.1080/ 07315724.2000 .10718916

Lipton, S. A., Kim, W. K., Choi, Y. B., Kumar, S., D’Emilia, D. M., Rayudu, P. V., et al. (1997). Neurotoxicity associated with dual actions of homocysteine at the N-methyl-D-aspartate receptor. Proc. Natl. Acad. Sci. U.S.A. 94, 5923-5928. doi: 10.1073/pnas.94.11.5923

Liu, J., Head, E., Gharib, A. M., Yuan, W., Ingersoll, R. T., Hagen, T. M., et al. (2002). Memory loss in old rats is associated with brain mitochondrial decay and RNA/DNA oxidation: partial reversal by feeding acetyl-L-carnitine and/or R-alpha -lipoic acid. Proc. Natl. Acad. Sci. U.S.A. 99, 2356-2361. doi: 10.1073/ pnas.261709299

Loef, M., and Walach, H. (2012). Fruit, vegetables and prevention of cognitive decline or dementia: a systematic review of cohort studies. J. Nutr. Health Aging 16, 626-630. doi: 10.1007/s12603-012-0097-x

Maneesub, Y., Sanvarinda, Y., and Govitrapong, P. (1993). Partial restoration of choline acetyltransferase activities in aging and AF64A-lesioned rat brains by vitamin E. Neurochem. Int. 22, 487-491. doi: 10.1016/0197-0186(93)90044-6

Miglio, C., Chiavaro, E., Visconti, A., Fogliano, V., and Pellegrini, N. (2008). Effects of different cooking methods on nutritional and physicochemical characteristics of selected vegetables. J. Agric. Food Chem. 56, 139-147. doi: 10.1021/jf072304b

Morris, J. C., McKeel, D. W. Jr., Storandt, M., Rubin, E. H., Price, J. L., Grant, E. A., et al. (1991). Very mild Alzheimer's disease: informant-based clinical, psychometric, and pathologic distinction from normal aging. Neurology 41, 469-478. doi: 10.1212/WNL.41.4.469

Morris, M. C., Evans, D. A., Bienias, J. L., Tangney, C. C., Bennett, D. A., Aggarwal, N., et al. (2002). Dietary intake of antioxidant nutrients and the risk of incident Alzheimer disease in a biracial community study. JAMA 287, 3230-3237. doi: 10.1001/jama.287.24.3230

Morris, M. C., Evans, D. A., Tangney, C. C., Bienias, J. L., and Wilson, R. S. (2006). Associations of vegetable and fruit consumption with age-related cognitive change. Neurology 67, 1370-1376. doi: 10.1212/01.wnl.0000240224.38978.d8

Nooyens, A. C., Bueno-de-Mesquita, H. B., van Boxtel, M. P., van Gelder, B. M., Verhagen, H., and Verschuren, W. M. (2011). Fruit and vegetable intake and cognitive decline in middle-aged men and women: the Doetinchem Cohort Study. Br. J. Nutr. 106, 752-761. doi: 10.1017/s0007114511001024

Nurk, E., Refsum, H., Drevon, C. A., Tell, G. S., Nygaard, H. A., Engedal, K., et al. (2010). Cognitive performance among the elderly in relation to the intake of plant foods. The Hordaland Health Study. Br. J. Nutr. 104, 1190-1201. doi: 10.1017/s0007114510001807

Ozawa, M., Ninomiya, T., Ohara, T., Doi, Y., Uchida, K., Shirota, T., et al. (2013). Dietary patterns and risk of dementia in an elderly Japanese population: the Hisayama Study. Am. J. Clin. Nutr. 97, 1076-1082. doi: 10.3945/ajcn.112. 045575

Paleologos, M., Cumming, R. G., and Lazarus, R. (1998). Cohort study of vitamin C intake and cognitive impairment. Am. J. Epidemiol. 148, 45-50. doi: 10.1093/ oxfordjournals.aje.a009559

Porrini, M., and Riso, P. (2008). Factors influencing the bioavailability of antioxidants in foods: a critical appraisal. Nutr. Metab. Cardiovasc. Dis. 18, 647-650. doi: 10.1016/j.numecd.2008.08.004

Proteggente, A. R., Pannala, A. S., Paganga, G., Van Buren, L., Wagner, E., Wiseman, S., et al. (2002). The antioxidant activity of regularly consumed fruit 
and vegetables reflects their phenolic and vitamin C composition. Free Radic. Res. 36, 217-233. doi: 10.1080/10715760290006484

Ritchie, K., Carriere, I., Ritchie, C. W., Berr, C., Artero, S., and Ancelin, M. L. (2010). Designing prevention programmes to reduce incidence of dementia: prospective cohort study of modifiable risk factors. BMJ 341:c3885. doi: 10 . 1136/bmj.c3885

Roberts, R. O., Geda, Y. E., Cerhan, J. R., Knopman, D. S., Cha, R. H., Christianson, T. J., et al. (2010). Vegetables, unsaturated fats, moderate alcohol intake, and mild cognitive impairment. Dement. Geriatr. Cogn. Disord. 29, 413-423. doi: 10.1159/000305099

Sabia, S., Nabi, H., Kivimaki, M., Shipley, M. J., Marmot, M. G., and SinghManoux, A. (2009). Health behaviors from early to late midlife as predictors of cognitive function: the whitehall II study. Am. J. Epidemiol. 170, 428-437. doi: 10.1093/aje/kwp161

Sack, C. A., Socci, D. J., Crandall, B. M., and Arendash, G. W. (1996). Antioxidant treatment with phenyl-alpha-tert-butyl nitrone (PBN) improves the cognitive performance and survival of aging rats. Neurosci. Lett. 205, 181-184. doi: 10. 1016/0304-3940(96)12417-4

Scarmeas, N., Luchsinger, J. A., Schupf, N., Brickman, A. M., Cosentino, S., Tang, M. X., et al. (2009). Physical activity, diet, and risk of Alzheimer disease. JAMA 302, 627-637. doi: 10.1001/jama.2009.1144

Seshadri, S., Beiser, A., Selhub, J., Jacques, P. F., Rosenberg, I. H., D’Agostino, R. B., et al. (2002). Plasma homocysteine as a risk factor for dementia and Alzheimer's disease. N. Engl. J. Med. 346, 476-483. doi: 10.1056/NEJMoa01 1613

Stroup, D. F., Berlin, J. A., Morton, S. C., Olkin, I., Williamson, G. D., Rennie, D., et al. (2000). Meta-analysis of observational studies in epidemiology: a proposal for reporting. Meta-analysis Of Observational Studies in Epidemiology (MOOSE) group. JAMA 283, 2008-2012. doi: 10.1001/jama.283. 15.2008

Tobias, A. (1999). Assessing the influence of a single study in meta-analysis. Stata Tech. Bull. 47, 15-17.

Tucker, K. L., Hallfrisch, J., Qiao, N., Muller, D., Andres, R., and Fleg, J. L. (2005). The combination of high fruit and vegetable and low saturated fat intakes is more protective against mortality in aging men than is either alone: the Baltimore Longitudinal Study of Aging. J. Nutr. 135, 556-561.
Vercambre, M. N., Boutron-Ruault, M. C., Ritchie, K., Clavel-Chapelon, F., and Berr, C. (2009). Long-term association of food and nutrient intakes with cognitive and functional decline: a 13-year follow-up study of elderly French women. Br. J. Nutr. 102, 419-427. doi: 10.1017/s0007114508201959

Wells, G., Shea, B., O'Connell, D., Peterson, J., Welch, V., Losos, M., et al. (2011). The Newcastle-Ottawa Scale (NOS) for Assessing the Quality of Nonrandomised Studies in Meta-Analyses. Ottawa: University of Ottawa.

Wu, M. S., Lan, T. H., Chen, C. M., Chiu, H. C., and Lan, T. Y. (2011). Sociodemographic and health-related factors associated with cognitive impairment in the elderly in Taiwan. BMC Public Health 11:22. doi: 10.1186/1471-245811-22

Wu, S., Ding, Y., Wu, F., Li, R., Hou, J., and Mao, P. (2015). Omega-3 fatty acids intake and risks of dementia and Alzheimer's disease: a meta-analysis. Neurosci. Biobehav. Rev. 48C, 1-9. doi: 10.1016/j.neubiorev.2014.11.008

Ye, X., Bhupathiraju, S. N., and Tucker, K. L. (2013). Variety in fruit and vegetable intake and cognitive function in middle-aged and older Puerto Rican adults. $\mathrm{Br}$. J. Nutr. 109, 503-510. doi: 10.1017/S0007114512001183

Yokota, T., Igarashi, K., Uchihara, T., Jishage, K., Tomita, H., Inaba, A., et al. (2001). Delayed-onset ataxia in mice lacking alpha -tocopherol transfer protein: model for neuronal degeneration caused by chronic oxidative stress. Proc. Natl. Acad. Sci. U.S.A. 98, 15185-15190. doi: 10.1073/pnas.261456098

Zandi, P. P., Anthony, J. C., Khachaturian, A. S., Stone, S. V., Gustafson, D. Tschanz, J. T., et al. (2004). Reduced risk of Alzheimer disease in users of antioxidant vitamin supplements: the Cache County Study. Arch. Neurol. 61, 82-88. doi: 10.1001/archneur.61.1.82

Conflict of Interest Statement: The authors declare that the research was conducted in the absence of any commercial or financial relationships that could be construed as a potential conflict of interest.

Copyright (c) 2017 Jiang, Huang, Song, Deng, Wei and Zhang. This is an open-access article distributed under the terms of the Creative Commons Attribution License (CC BY). The use, distribution or reproduction in other forums is permitted, provided the original author(s) or licensor are credited and that the original publication in this journal is cited, in accordance with accepted academic practice. No use, distribution or reproduction is permitted which does not comply with these terms. 